\title{
Peribulbar Sub-Tenon's Anaesthesia With Levo- Bupivacaine and Cis-Atracurium Besilate in Ophthalmic Intraocular Surgery in Cat: Clinical Study.
}

giovanna costa ( $\sim$ glcosta@unime.it)

Universita degli Studi di Messina https://orcid.org/0000-0001-9330-5038

\section{Bernadette Nastasi}

University of Messina

Filippo Spadola

University of Messina: Universita degli Studi di Messina

Fabio Leonardi

University of Parma

Marcello Musicò

University of Messina: Universita degli Studi di Messina

\section{Research article}

Keywords: sub-Tenon's peribulbar anesthesia, Levo-bupivacaine, cis-atracurim besilate, neuromuscular blockade, ophthalmic surgery, cats

Posted Date: December 10th, 2020

DOl: https://doi.org/10.21203/rs.3.rs-120376/v1

License: (c) (i) This work is licensed under a Creative Commons Attribution 4.0 International License.

Read Full License 


\section{Abstract}

\section{Background}

this study aims to evaluate the efficacy of Levo-bupivacaine with the addition of a small dose of cisatracurium by sub-Tenon's injection on akinesia and mydriasis. Then, to evaluate if such a small dose of cisatracurium could determine a systemic neuromuscular blockade, despite the way of administration. Forty cats were anesthetized for intra-ophthalmic surgery with butorphanol 0,2 $\mathrm{mgkg}^{-1}$, dexmedetomidine $15 \mathrm{mcg} / \mathrm{kg}$ and midazolam $0,2 \mathrm{mgkg}^{-1} \mathrm{IM}$ and intubated to receive oxygen and isofluorane by mechanical ventilation. The animals were divided in four groups. Group $L$ received $1.25 \mathrm{mgkg}^{-1} \mathrm{~L}$-bupivacaine, administered by peribulbar injection; group CL received the same dose of L-bupivacaine, combined with $0.01 \mathrm{mg} / \mathrm{kg}$ of cisatracurium; group $\mathrm{C}$ received $0.01 \mathrm{mg} \mathrm{kg}^{-1}$ of peribulbar cisatracurium; group GC received $0.01 \mathrm{mg} \mathrm{kg}^{-1}$ of cisatracurium intravenously. Physiological variables and oculomotor activity were measured before and up to 30 minutes after peribulbar injection.

Results

The data below, expressed with median and range, show that physiological variables remained in the physiological range. Among the treatments, the LC group showed akinesia, higher midriasis and a decrasing intraocular pressure (IOP); the onset time of akinesia was significantly shorter in group LC than in group $L 4(3 / 5)$ min and 8(6/10) min respectively, $p=0.000$; the duration of akinesia was longer in group LC than in group $L, 70(68 / 72)$ and $60(57 / 63 \mathrm{~min})$, respectively $p=0.000$. In group $C$ we observed the appearance of akinesia after 5(5/5) minutes from the peribulbar administration and it lasted for $20(20 / 20)$ minutes $(p=0.000)$, compared to groups $L$ and $L C$. In group $G C$ we registered akinesia after $5(5 / 5)$ minutes, but the duration observed was shorter 5(5/6). In groups $C$ and $G C$, additional $L$ bupivacaine peribulbar injection was required. The train of four (TOF) was $\geq 0.9$ throughout the study in all of the groups.

Conclusions

A combination of cisatracurium and L-bupivicaine, used for peribulbar sub-Tenon's anesthesia, provides effective akinesia, midriasis of the eye, shortens the onset of akinesia and prolongs its duration, thus providing excellent conditions for intra-ophthalmic surgery, without incurring in a systemic blockade.

\section{Background}

General anaesthesia usually induces eyeball ventromedial deviation which may hamper the vision of the surgical field in subjects undergoing ocular surgery. Nowadays, regional anaesthetic techniques, which provide akinesia, mydriasis and periocular analgesia, are commonly used for ophthalmic surgery. ${ }^{1-4}$ Regional anaesthetic techniques include retrobulbar and peribulbar anaesthesia. Peribulbar anaesthesia reduces the incidence of haemorrhages at the cone level and injuries to the optic nerve, and induces 
akinesia and mydriasis more efficiently compared to retrobulbar anaesthesia. ${ }^{5-7}$ The onset of akinesia related to peribulbar injections of local anaesthetic agent combined with a low dose of neuromuscular blocking is lower compared to that of the local anaesthetic agent alone. ${ }^{8-11}$ Nevertheless, many serious complications (e.g.: retrobulbar hemorrhage, globe perforation) may occur also following peribulbar injections. To avoid these complications, sub-Tenon's anaesthesia has been developed and used during ophthalmic surgery in humans, dogs and cats. $5,12-13$

Levobupivacaine, a long-acting local anaesthetic agent, is the levorotatory isomer of racemic bupivacaine. As regard with anaesthetic potency, levobupivacaine is similar to bupivacaine but has less toxic potential both on the central nervous system and on the heart. Reduced toxic potential of levobupivacaine compared to bupivacaine supports the use of levobupivacaine in those clinical situations in which the risk of systemic toxicity, related with overdosing or unintentional intravascular injection, is high, such as during epidural or peripheral nerve blocks. ${ }^{14}$ Based on these findings, levobupivacaine is used for peribulbar anaesthesia in elderly human patients undergoing vitreous and retina surgical procedures. ${ }^{15-16}$

Cisatracurium, an isomer of atracurium, is a non-depolarizing neuromuscular blocking agent with a duration of action of approximately 27 minutes. Cisatracurium may be reversed by edrophonium, neostigmine, and pyridostigmine. ${ }^{17-19}$ The clearance of cisatracurium occurs through Hoffmann elimination, bypassing hepatic metabolism and renal filtration. Consequently, cisatracurium may be safely used in patients with liver and kidney diseases. Non-depolarizing neuromuscular blocking agents administered intravenously are useful adjuvants for general anaesthesia but mechanical ventilator is required to support patient's ventilation, because these drugs cause respiratory muscle paralysis. To avoid this side effect, atracurium and cisatracurium are used in peribulbar aneasthesia to obtain extraocular muscle akinesia. ${ }^{8-11}$

This study was necessary: to achieve, a balanced anesthesia in the cat, adequate to ophthalmic intraocular surgery in cat, to reduce side effects, improve the comfort of the surgeon and ensure the success of surgery.The aim of this study is to evaluate the onset of eyeball centralization, akinesia duration and mydriasis degree after sub-Tenon's injection of levobupivacaine alone and combined with low dose of cisatracurium in cats undergoing intraocular ophthalmic surgery. Moreover, the study aims to assess if the low-dose of cisatracurium administered through sub-Tenon's injection can determine systemic neuromuscular blockade.

\section{Methods}

The study was approved by the Review Board for Animals Care of the the University of Messina. Procedures were performed in accordance with Italian law (D.M. 116192), Europe law (O.J. of E.C. L 358/1 12/18/1986), and USA laws (Animal Welfare Assurance No A5594-01, Department of Health and Human Services, USA). Prior to the cats enrolment in the study, the owners provided informed consent. 
thirty female cat and ten males of $3,5 \pm 0,5 \mathrm{~kg}$,were admitted to our hospital for the following ophthalmic surgeries: penetrating corneal ulcers $(n=32)$ and cataract $(n=8)$. The patients were chosen for their docile temperament and they were randomly divided into four groups of treatment of ten subjects each (L, LC, GC, and C group) by drawing a ticket. All cats were sedated using butorphanol $0.2 \mathrm{mg} \mathrm{kg}^{-1}$ (Dolorex 1\%; Intervet, Aprilia Italy), dexmedetomidine $15 \mathrm{\mu g} \mathrm{kg}^{-1}$ (Dexdomitor 0.5\%, Pfizer Animal Health, Roma Italy) and midazolam $0.2 \mathrm{mg} \mathrm{kg}^{-1}$ (Ipnovel 0,5\% Roche, Basilea Switzerland) combined and administered intramuscurarly. Following sedation, a $0.64 \times 19-\mathrm{mm}, 24-\mathrm{G}$ venous (DELTA VEN, Deltamed Italy) catheter was inserted in the cephalic vein for medication and fluid administration. Artificial tear eye drops were applied on corneal surface every thirty minutes until the start of surgery (Artelac splash; Baush \& Lomb, Italy). Anaesthesia was induced with propofol (Proposure 1\%, Merial Italy) at effect intravenously. All cats received $2 \mathrm{mg} \mathrm{kg}^{-}{ }^{-}$of lidocaine (Lidocaina $2 \%$, Zoetis, Roma Italy) sprayed on the glottis and the endotracheal intubation was performed with a cuffed tube. Anaesthesia was maintained with isoflurane (ESTEVE; Barcelona, Spain) delivered in 100\% oxygen via a non-rebreathing circle system (Mapleson B in parallel of Lack). Controlled respiration was supported by intermittent positive pressure ventilation. The mechanical ventilator (Servoventilator $900 \mathrm{C}$, Siemens Elema Sweden) was set using the following parameters: respiratory rate 20 breaths $\min ^{-1}$, volume $1.5 \mathrm{~L} \mathrm{~min}^{-1}$, tidal volume of $\sim 18 \mathrm{~mL} \mathrm{~kg}^{-}$ 1 , inspiratory/expiratory ratio (I:E) $1: 2$, and airway pressure $20 \mathrm{cmH}_{2} \mathrm{O}$.

Then, all the cats were administered peribulbar sub-Tenon's anaesthesia in the eye to be operated using a $0.4 \times 13 \mathrm{~mm} 27 \mathrm{G}$ sterile needle (Latex Free Benefis ${ }^{\circledR}$ Italy). The anaesthetic mixture was applied both in the inferior temporal corner and in the upper nasal corner by inserting the needle between orbit and eyeball (Davis et al, 1986). The $\mathrm{L}$ group received L-bupivacaine $1.25 \mathrm{mg} \mathrm{kg}^{-1}(0.75 \%$ Chirocaina; Abbott, USA); LC group received $1.25 \mathrm{mg} \mathrm{Kg}^{-1}$ of L-bupivacaine combined with cisatracurium $0.01 \mathrm{mg} \mathrm{kg}^{-1}(0.2 \%$ Nimbex; Glaxo, Smithkline spa Italy); C group received $0.01 \mathrm{mg} \mathrm{kg}^{-1}$ of cisatracurium; GC group received $0.01 \mathrm{mg} \mathrm{kg}^{-1}$ of cisatracurium intravenously. All peribulbar anaesthesia were performed with the same volume of drug $(1 \mathrm{ml})$, with the addition of saline solution $0,9 \%$. If ineffective block occurred, additional local anaesthetic peribulbar block with L-bupivacaine was administered. A single observer, blinded to treatment, recorded the following parameters: heart rate $\left(\mathrm{HR}-\right.$ beats $\left.\mathrm{min}^{-1}\right)$, respiratory rate $(\mathrm{RR}-$ breaths $\mathrm{min}^{-1}$, end-tidal carbon dioxide tension $\left(\mathrm{EtCO}_{2}-\mathrm{mmHg}\right)$, arterial haemoglobin oxygen saturation $\left(\mathrm{SpO}_{2}-\%\right)$, non-invasive blood pressure (NIBP - $\mathrm{mmHg}$ ) by placing a cuff around the base of the tail, and the concentration of inspired and expired isofluorane (IT/ET isofluorane) using a multiparameter model (AMI s.r.l., Leonardo model Italy).

The evaluation of neuromuscular transmission was performed by detecting the TOF (Train of four) using a machine (TOF-Watch ${ }^{\circledR} \mathrm{SX}$; Organon, Italy) set automatically before each use at $50 \mathrm{~mA}$ and $1-0.1 \mathrm{~Hz}$. The stimulating electrodes were applied at the medial part of the elbow (at the level of the ulnar nerve), whereas the recording of potentials was obtained by applying the electrodes above the carpus muscles. All parameters were measured immediately before sedation (time 0 ), after sedation (S), except $\mathrm{TOF}, \mathrm{SpO}_{2}$, and $\mathrm{EtCO}_{2}$, and at 5, 10, 15, 20, 25 and 30 minutes after anaesthesia. 
The intraocular pressure (IOP - mmHg) was measured with Tono-Pen Vet (Reichert Italy). The IOP baseline value was recorded after instillation of one drop of oxybuprocaine $(0.4 \%$ Novesina; Novartis Italy) in awake animals. Afterward, the IOP was measured after sedation, at 5 and 10 minutes after peribulbar anaesthesia, and before the start of surgery with cats in sternal recumbency. The degree of mydriasis was evaluated by measuring the horizontal pupil diameter $(\mathrm{mm})$ with Jameson calipers (E2410 Storz ${ }^{\circledR}$, Italy) in awake animals, after sedation, at 5 and 10 minutes after anaesthesia, and before the start of surgery. The horizontal pupil diameter was measured $(\mathrm{mm})$ by a single observer in the same room, lit with a 40W lamp. After sedation, eyeball centralization (akinesia) was evaluated by three independent observers that recorded if the eye was rotated or centrally positioned. Any deviation of the eye from central position was considered as rotated. ${ }^{1-4}$ Onset and duration of akinesia (minutes) of extraocular muscles were recorded by a single observer.

All cats after full recovery have been discharged from hospital.

Statistical analysis was performed using SPSS 15.0 IBM software for Windows. A Kendall's test of concordance Shapiro-Wilk test and a power calculation of sample were performed. The data, expressed with median and range, were compared using Friedman test to evaluate changes along the time line and compared differences among groups. Statistical significance was set at $p<0.05$.

\section{Results}

High level of concordance inter-observer $(\mathrm{W}=1)$ was recorded in all groups and data were not normally distributed; The sample , of subjects examined, is not representative enough of the population. HR, NIBP remained within physiologic ranges in all groups; $\mathrm{EtCO}_{2}$ and $\mathrm{SpO}_{2}$ values were $32-34 \mathrm{mmHg}$ and $98-$ $100 \%$ respectively (details were not reported in Table 1 ) The onset time of akinesia in group LC was significantly shorter than in group $L, 4(3 / 5)$ and $8(6 / 10)$ minutes respectively $(p=0.000)$ (Table 1$)$. The duration of akinesia in group LC was longer than in group $L, 70(68 / 72)$ and $60(57 / 63)$ minutes respectively $(p=0.000)($ Table 1$)$.

In group $C$ we observed the appearance of akinesia after 5(5/5) minutes from the peribulbar administration and it lasted for 20(20/20) minutes $(p=0.000)$, compared to groups $L$ and LC(Table 1$)$ (Table 1).

In group GC we registered akinesia after 5(5/5) minutes, but the duration observed was shorter 5(5/6). In groups $C$ and $G C$, additional $L$ bupivacaine peribulbar injection was required.

IOP was significantly lower $(p=0.000)$ in the LC group than in the L group at 5 and 10 minutes after peribulbar anaesthesia. In groups GC and C, the IOP was reduced in comparison to baseline and remained consistent after peribulbar and intravenously cisatracurim administration (Table 1 ). The degree of mydriasis was significantly higher $(p=0.000)$ in the LC group than in the $L$ group at 5 and 10 minutes after peribulbar anaesthesia; in $\mathrm{C}$ and GC groups, the pupil diameter increased after sedation and there were variations after that peribulbar cisatracurium was administered(Table 1). Throughout the study, the 
TOF (T1:T4) was $\geq 0.9$ in all groups. The concentration of inspired and expired isofluorane was about $0.5-1 \%$ among the groups.

Table 1 legend: physiological and ophthalmic variables recorded in the groups: $L C=$ levobupivacaine 2.5 $\mathrm{mg} \mathrm{kg}^{-1}$ combined with cisatracurium $0.01 \mathrm{mg} \mathrm{kg}^{-1}$ (peribulbar); $\mathrm{L}=$ levobupivacaine $2.5 \mathrm{mg} \mathrm{kg}^{-}$ ${ }^{1}$ (peribulbar); GC= cisatracurium $0.01 \mathrm{mg} \mathrm{kg}^{-1}(\mathrm{EV}) ; \mathrm{C}=$ cisatracurium $0.01 \mathrm{mg} \mathrm{kg}^{-1}$ (peribulbar). $\mathrm{S}=$ sedation; $5^{\prime}-30^{\prime}=$ measurements during anaesthesia. Underlined = significant differences between values at different times. Bold = significant difference between groups $(P<0.05)$.

\begin{tabular}{|c|c|c|c|c|c|c|c|c|c|}
\hline & & & After sedation & After an & hesia & & & & \\
\hline $\begin{array}{l}\text { Measured } \\
\text { Data } \\
\text { Median } \\
\text { range }\end{array}$ & Drugs & $0^{\prime}$ & $S$ & $5^{\prime}$ & $10^{\prime}$ & $15^{\prime}$ & $20^{\circ}$ & $25^{\prime}$ & $30^{\circ}$ \\
\hline $\begin{array}{l}\text { IOP } \\
(\mathrm{mmHg})\end{array}$ & $\begin{array}{l}L C \\
L \\
G C \\
C\end{array}$ & $\begin{array}{l}20(16 / 22) \\
18(16 / 20) \\
17(16 / 18) \\
18(16 / 20)\end{array}$ & $\frac{\frac{18(16 / 20)}{17(15 / 19)}}{\frac{16(16 / 17)}{18(16 / 20)}}$ & $\begin{array}{l}\frac{16(15 / 17)}{17(15 / 19)} \\
\frac{16(15 / 17)}{18(17 / 18)}\end{array}$ & $\begin{array}{l}\frac{15(13 / 17)}{17(15 / 19)} \\
\underline{16(15 / 17)} \\
\underline{16(15 / 17)}\end{array}$ & & & & \\
\hline
\end{tabular}

\begin{tabular}{|c|c|c|c|c|c|}
\hline & $L C$ & $5(4 / 6)$ & $\underline{6(5 / 7)}$ & $\underline{8(7 / 9)}$ & $\underline{8(7 / 9)}$ \\
\hline $\begin{array}{l}\text { Horizontal } \\
\text { pupil }\end{array}$ & $\begin{array}{l}L \\
G C \\
C\end{array}$ & $\begin{array}{l}5(4 / 6) \\
4(4 / 6) \\
\sigma(4 / 6)\end{array}$ & $\frac{\overline{\frac{6(5 / 7)}{5(5 / 6)}}}{\frac{5(5 / 7)}{6(7)}}$ & $\frac{\overline{6(5 / 7)}}{\frac{5(5 / 6)}{8(7 / 9)}}$ & $\begin{array}{l}6(5 / 7) \\
5(5 / 6) \\
8(7 / 9)\end{array}$ \\
\hline
\end{tabular}

(mm)

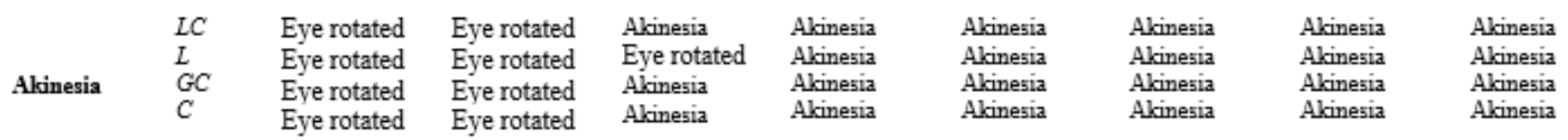

\begin{tabular}{|c|c|c|}
\hline $\begin{array}{l}\text { Onset of } \\
\text { akinesia } \\
\text { (min) }\end{array}$ & $\begin{array}{l}L C \\
L \\
C \\
G C\end{array}$ & $\begin{array}{l}4(3 / 5) \\
8(6 / 10) \\
5(3 / 7) \\
5(5 / 5)\end{array}$ \\
\hline & $L C$ & $70(68 / 72)$ \\
\hline $\begin{array}{l}\text { Duration of } \\
\text { akinesia } \\
\text { (min) }\end{array}$ & $\begin{array}{l}L \\
C \\
G C\end{array}$ & $\begin{array}{l}60(/ 57 / 63) \\
20(20 / 20) \\
5(5 / 6)\end{array}$ \\
\hline
\end{tabular}


Levobupivacaine, combined with cisatracurium and administered by sub-Tenon's peribulbar injection, has provided a clinically effective degree of mydriasis, a faster eyeball centralization (akinesia), and maintained normal IOP values. ${ }^{8-9}$ The onset of akinesia induced by levobupicaine combined with small quantity of cisatracurium is faster compared to that of levobupivacaine alone. ${ }^{10-11}$ In our opinion, this effect is due to the presence of the Felderstruktur. ${ }^{20-21}$ This is an anatomical ocular structure, provided with small grape-like nerve endings, which respond with a slow tonic contraction to non-depolarizing agents, such as cis-atracurim ${ }^{10-11}$. Furthermore, the duration of akinesia induced by levobupicaine alone is shorter. The eyeball centralization and mydriasis facilitate the phacoemulsification and surgical procedures, whereas normal IOP is mandatory for the success of ophthalmic surgery. The administration of a combination of neuromuscular blocking agent and local anaesthetic drug by sub-Tenon's peribulbar injection is an effective option for the execution of many veterinary intra-ocular ophthalmic procedures, and it allows to use low doses of general anaesthetic drugs, without undergoing side effects, such as a systemic neuromuscular blockade ${ }^{13,14}$ Dexmedetomidine combined with midazolam and butorphanol is a suitable sedation protocol for cat undergoing ophthalmic surgery because it does not increase IOP and ensures mydriasis. ${ }^{20}$ Furthermore, dexmedetomidine and butorphanol provide good sedation because they act on the same membrane G-protein. ${ }^{22-24}$ Nevertheless, dexmedetomidine combined with butorphanol significantly decreases tear production 15 minutes after sedation. ${ }^{25-27}$ In the present study, we used high dose of dexmedetomidine to obtain a profound sedation to perform basal TOF measurement. Despite this high dose of dexmedetomidine, hemodynamic and respiratory parameters remained within physiological ranges. Then, in other contests, this dosage is not necessary and it can be reduced. The peribulbar anaesthesia is a reliable alternative to retrobulbar anaesthesia. To perform peribulbar anesthesia, the practitioner injects the drugs around the orbit and, consequently, the risk of haemorrhages at the cone level or lesions of the optic nerve is greatly reduced, compared to retrobulbar anesthesia. ${ }^{5}$ As regard with analgesia and akinesia, no clear differences between peribulbar and retrobulbar anaesthesia were demonstrated in human beings. Furthermore, few side effects were recorded with both anaesthetic techniques. ${ }^{6-7}$ In the veterinary literature, Shilo-Benjamini et al. (2013) highlighted that single peribulbar technique was better than double peribulbar and retrobulbar techniques, because single peribulbar injection provided "large" distribution of injected drug and, consequently, it could determine $86 \%$ of regional anaesthesia. Furthermore, IOP at 15 minutes after peribulbar injection was higher compared to baseline values. ${ }^{5}$ In our study, IOP decreased after peribulbar injection. The likely reason of this difference is that, unlike Shilo-Benjamini et al. (2013), we enrolled live animals. Nevertheless, we cannot exclude that decrease in IOP was related to the lower injected volume compared to that previously used. ${ }^{5}$ Moreover, surgical procedures were easily performed and no anaesthetic side effects were recorded. All patients had an excellent adaptation to the automatic ventilator, with $\mathrm{EtCO}_{2}$ ventilation setting between $32-34 \mathrm{mmHg}$. The $\mathrm{SPO}_{2}$ remained consistent at optimal levels (98-100\%). No systemic neuromuscular blockade was recorded in all groups by measuring TOF. However, if neuromuscular blocking agents are administered, the use of an automatic ventilator is advisable. 
A limitation to this kind of study could be the scarcity of cases to recruit and properly submit to intraocular surgery, since it has been a clinical and non-experimental study.

\section{Conclusion}

The anaesthetic management contributes to the success of ophthalmic surgery. Peribulbar anaesthesia combined with low doses of isoflurane is an effective method for anesthetizing cats undergoing intraophthalmic surgeries. The addition of $0.01 \mathrm{mg} \mathrm{kg}^{-1}$ of cis-atracurium to sub Tenon's administration of levobupivacaine improves the onset and quality of the local block and the degree of mydriasis, reduces IOP, and, consequently, facilitates the execution of ophthalmic surgeries. Low-dose of cis-atracurium administered through sub-Tenon's injection does not determine systemic neuromuscular blockade.

\section{Abbreviations}

IOP; intraocular pressure

HR; heart rate

min ;minutes

$\mathrm{RR}$; respiratory rate

$\mathrm{EtCO}_{2}$;carbon dioxide tension

$\mathrm{mmHg}$; millimetres of mercury

$\mathrm{SpO}_{2 ;}$ arterial haemoglobin oxygen saturation

$\%$; percentage

NIBP; non-invasive blood pressure

IT/ET; concentration of inspired and expired isofluorane

TOF; Train of four

S; sedation

min; minutes

\section{Declarations}

\section{Availability of data and materials}


The collection material and the recorded data is available and kept by the first author, Dr. Giovanna Costa glcosta@unime.it

\section{Competing interests}

No competing interests

\section{Consent for publication}

All authors give their consent to publication

\section{Funding}

No funding

\section{Authors' contributions}

Giovanna Costa: project preparation, data recording and statistical processing. Preparing the manuscript;

Bernadette Nastasi: data recording and preparing the manuscript;

Marcello Musicò data recording and preparing the manuscript

Fabio Leonardi data recording and preparing the manuscript

Filippo Spadola data recording and peparing the manuscript

\section{Acknowledgment(S)}

We thank Caroline Keir for her English revision.

\section{References}

1. Herbert GL, Murison PJ. Eye position of cats anaesthetised with alfaxalone or propofol. Veterinary Record. 2013; 172, 365.

2. Auer $\mathrm{U}$, Mosing M, Moens YP. The effect of low dose rocuronium on globe position, muscle relaxation and ventilation in dogs: a clinical study. Veterinary Ophthalmology. 2007; 10: 295-8.

3. Hazra S, De D, Roy B et al Use of ketamine, xylazine, and diazepam anaesthesia with retro bulbar block for phacoemulsification in dogs. Veterinary Ophthalmology. 2008; 11, 255-9.

4. Ahn J, Jeong M, Lee E et al. Effects of peribulbar anaesthesia (sub-Tenon injection of a local anesthetic) on akinesia of extra ocular muscles, mydriasis, and intraoperative and postoperative analgesia in dogs undergoing phacoemulsification. American Journal of Veterinary Research. 2013; 74, 1126-32. 
5. Shilo-Benjamini Y, Pascoe PJ, Maggs DJ et al. Retrobulbar and peribulbar regional techniques in cats: a preliminary study in cadavers. Veterinary Anaesthesia and Analgesia. 2013; 40: 623-31

6. Davis DB, Mandel MR. Posterior peribulbar anaesthesia: an alternative to retrobulbar anaesthesia. Journal of Cataract Refractive Surgery 12,182-184.

7. Alhassan MB, Kyari F, Ejere HO. Peribulbar versus retrobulbar anaesthesia for cataract surgery. Cochrane Database of Systematic Reviews. 2015; 2-7

8. Abdellatif AA, El Shahawy MA, Ahmed Al et al. Effects of local low-dose rocuronium on the quality of peribulbar anaesthesia for cataract surgery. Saudi J Anaesth 2011; 5, 360-4.

9. Costa G, Musicò M, Spadola F et al. Comparison of intravenous and peribulbar cis-atracurium administration in dogs undergoing ophthalmic surgery. Preliminary results. In: Proceedings AVA Spring Meeting, Rimini (Bologna, Italy) 2005; 87.

10. Küçükyavuz Z, Arici M K. Effects of atracurium added to local anaesthetics on akinesia in peribulbar block. Regional Anesthesia and Pain Medicine 2002 27: 487-90.

11. Godarzi M, Beyranvand S, Arbabi S et al. Comparing the effect of using atracourium and cisatracourium as adjuvant agents to the local anaesthetic substance on peribulbar-induced akinesia. Acta Medica Iran 2011; 49: 509-12.

12. Shilo-Benjamini Y, Pascoe PJ, Maggs DJ et al. Retrobulbar vs peribulbar regional anesthesia techniques using bupivacaine in dogs. Vet Ophthalmol. doi: 10.1111

13. Ahn J, Jeong M, Park $Y$ et al. Comparison of systemic atracurium, retrobulbar lidocaine, and subTenon's lidocaine injections in akinesia and mydriasis in dogs.Veterinary Ophthalmology. 16:440-5.

14. Briganti A, Barsotti G, Portela G A, Di Nieri C, Breghi G. Effects of rocuronium bromide on globe position and respiratory function in isoflurane-anesthetized dogs: a comparison between three different dosages. Veterinary Ophthalmology (2013); 1-6.

15. Leone S, Di Cianni S, Casati A et al. Pharmacology, toxicology, and clinical use of new long acting local anesthetics, ropivacaine and levobupivacaine. Acta Biomed 2008 79: 92-105.

16. Luchetti M, Magni G, Marraro G. et al. A prospective randomized double-blinded controlled study of ropivacaine $0.75 \%$ versus bupivacaine $5 \%$-mepivacaine $2 \%$ for peribulbar anaesthesia. Regional Anaesthesia and Pain Medicine. 2000; 25:195-200.

17. Pacella E, Pacella F, Troisi $F$ et al. Efficacy and safety of $0.5 \%$ levobupivacaine versus $0.5 \%$ bupivacaine for peribulbar Clinical Ophthalmology. 2013; 7: 927-32

18. Cullen LK. Muscle relaxants and neuromuscular block. In: Lumb \& Jones: Textbook of 'Veterinary Anesthesia 3th edition. Williams \& Wilkins, Philadelphia 1996; 337-364.

19. Savarese JJ., Miller RD, Lien CA et al. Pharmacology of muscle relaxants and their antagonists. In: Ronald D. Miller Anaesthesia 4th edition, Churchill Livingstone Inc., New York 2000; 417-87.

20. Katz R L, Eakins K E. Pharmacological studies of extraocular muscles. Investigative Ophtalmology $1967 ; 6: 261-268$. 
21. Cunningham AJ, Barry P. Intraoclar pressure physiology and implication for anesthetic management. CAN ANAESTH SOC J 1986; 33(2): 195-208.

22. Ramaswamy SS, Parimala B. Comparative evaluation of two different loading doses of dexmedetomidine with midazolam-fentanyl for sedation in vitreoretinal surgery under peribulbar anaesthesia. Indian Journal of Anaesth 2016; 60: 89-93

23. Horváth G, Kovács $M$, Szikszay $M$ et al. Mydriatic and antinociceptive effects of intrathecal exmedetomidine in conscious rats. European Journal of Pharmacol 1994; 21: 61-6.

24. Interlandi C, Calapai G, Nastasi B et al. Effects of atipamezole on the analgesic activity of butorphanol in rats. Journal of Exotic Pet Medicine. 2017; 4: 290-293.

25. Leonardi F, Costa GL, Stagnoli A et al. The effect of intramuscular dexmedetomidine-butorphanol combination on tear production in dogs. Canadian Veterinary Journal (In press).

26. Di Pietro S,Macrì F,Bonarrigo T,Giudice E, Palumbo Piccionello A,Pugliese A. Effects of a medetomidine-ketamine combination on Schirmer tear test I results of clinically normal cats. American Journal of Veterinary Research. 2016;77:310-4.

27. Leonardi F ,Costa GL, Dubau M, Sabbioni A, Simonazzi B, Angelone M. Effects of intravenous romifidine, detomidine, detomidine combined with butorphanol, and xylazine on tear production in horses. Equine Veterinary Education 2020; 32: 53-57 